\title{
ANALISIS HUBUNGAN STRES DENGAN NYERI KEPALA PRIMER PADA MAHASISWA PROGRAM STUDI KEDOKTERAN FAKULTAS KEDOKTERAN UNIVERSITAS MALAHAYATI
}

$$
\text { Dharmawita }^{1}, \text { Dalfian }^{2^{*}} \text {, Aprina Dwi Lestari }{ }^{3}
$$

1Departemen Neurologi Fakultas Kedokteran Universitas Malahayati ${ }^{2}$ Departemen Kesehatan Masyarakat Fakultas Kedokteran Universitas Malahayati ${ }^{3}$ Program Studi Kedokteran Fakultas Kedokteran Universitas Malahayati

$$
\text { Email Korespondensi : inainainalestari@gmail.com }
$$

\section{ABSTRACT: ANALYSIS OF THE RELATION OF STRESS WITH PRIMARY HEAD PAIN IN STUDENTS OF MEDICAL STUDY PROGRAM FACULTY OF MEDICINE MALAHAYATI UNIVERSITY}

Background : According to the World Health Organization, in 2012, it was stated that primary headaches showed a very high prevalence rate. Globally, it is estimated that the prevalence of headache in adults reaches $50 \%$. Where it was reported in the last year that adults aged 18-65 years in the world suffered from headaches, and among this population $30 \%$ had migraines, while more than $70 \%$ of the population reported suffering from TTH. Objective: This study aims to determine the relationship between stress and primary headache.

Method: This study used an observational analytic method with a cross sectional approach. With the sample population used by students of the 2017 Malahayati University medical faculty medical study program.

Result: The results of this study showed that 180 respondents experienced mild stress levels of 2 people (1.1\%), moderate stress 124 people (68.9\%) and 54 people experiencing severe stress (30\%). There were 114 respondents (63.3\%) who experienced primary headache (migraine) and 66 respondents (36.7\%) experienced tension-type headaches (TTH). From the results of the bivariate analysis of the study using the chi square method, it was found that the $p$ value was 0.000 ( $p<0.05)$.

Conclusion: There is a relationship between stress levels and primary headaches in students of the medical study program at the medical faculty of Malahayati University in 2020 with $p=0.000(<0.05), O R C l$ value $=3.841$.

Keywords: Stress, Migraine, Tension type headache, Cluster headache

INTISARI: ANALISIS HUBUNGAN STRES DENGAN NYERI KEPALA PRIMER PADA MAHASISWA PROGRAM STUDI KEDOKTERAN FAKULTAS KEDOKTERAN UNIVERSITAS MALAHAYATI

Latar Belakang : Menurut World Health Organization pada tahun 2012 menyatakan bahwa nyeri kepala jenis primary headache menunjukkan angka prevalensi yang sangat tinggi. Secara global, diperkirakan prevalensi nyeri kepala pada orang dewasa mencapai angka 50\%. Dimana dilaporkan dalam satu tahun terakhir orang dewasa berumur 18-65 tahun di dunia menderita nyeri kepala, dan diantara populasi tersebut $30 \%$ nya menderita migrain, sedangkan 
lebih dari 70\% populasi melaporkan menderita TTH.

Tujuan: Penelitian ini bertujuan untuk mengetahui hubungan antara stres dengan nyeri kepala primer.

Metode: Penelitian ini menggunakan metode Analitik observasional dengan pendekatan cross sectional. Dengan populasi sampel yang digunakan mahasiswa program studi kedokteran fakultas kedokteran Universitas Malahayati angkatan 2017.

Hasil penelitian : Hasil dari penelitian ini 180 responden didapatkan bahwa responden yang mengalami tingkatan stres ringan 2 orang $(1,1 \%)$, stres sedang 124 orang $(68,9 \%)$ dan yang mengalami stres berat 54 orang $(30 \%)$. Responden yang mengalami nyeri kepala primer yaitu migrain sebanyak 114 orang $(63,3 \%)$ dan yang mengalami nyeri kepala tipe tegang (TTH) sebanyak 66 orang $(36,7 \%)$. Dari hasil analisis bivariat penelitian dengan metode chi square dimana didapati nilai $p$-value sebesar $0,000(p<0,05)$.

Kesimpulan : Terdapat hubungan anatara tingkat stres dengan nyeri kepala primer pada mahasiswa program studi kedokteran fakultas kedokteran Universitas Malahayati Tahun 2020 dengan $p=0,000(<0,05)$, nilai OR Cl $=3,841$.

Kata Kunci : Stres, Migrain, Tension type headache, Cluster headache.

\section{LATAR BELAKANG}

Nyeri kepala adalah rasa nyeri atau rasa tidak nyaman pada seluruh daerah kepala dengan batas bawah dari dagu sampai ke daerah belakang kepala (daerah oksipital dan sebagian daerah tengkuk). Primary headache dibagi menjadi migren, tension-type headache (TTH), Cluster headache (Tepper, 2013).

Menurut World Health Organization pada tahun 2012 menyatakan bahwa nyeri kepala jenis primary headache menunjukkan angka prevalensi yang sangat tinggi. Secara global, diperkirakan prevalensi nyeri kepala pada orang dewasa mencapai angka 50\%. Dimana dilaporkan dalam satu tahun terakhir orang dewasa berumur 18-65 tahun di dunia menderita nyeri kepala, dan diantara populasi tersebut $30 \%$ nya menderita migren, sedangkan lebih dari $70 \%$ populasi melaporkan menderita TTH.

\section{Dalam}

penelitian

menyebutkan akibat dari keluhan nyeri kepala yang terus menerus dan gejala-gejala yang berhubungan bisa membuat kualitas hidup seseorang menurun. Migren termasuk penyakit urutan ke 7 di dunia yang bisa mengakibatkan keterbatasan aktivitas fisik. Hilangnya waktu yang produktif untuk kerja pada pegawai ataupun pekerja lainnya dan meningkatnya biaya pengeluaran merupakan hal-hal lain yang dialami para penderita nyeri kepala. (Ayzenberg et al,2014).

Ada banyak sekali faktor risiko yang mencetuskan terjadinya nyeri kepala primer. Untuk tipe TTH, faktor risiko yang telah berhasil diidentifikasi diantaranya adalah rendahnya tingkat kesehatan diri, stres (baik secara mental maupun fisik), kecemasan, depresi, ketidakstabilan temperamental; misalnya emosionalitas yang tinggi, sedikit berolahraga, pola makan ireguler, postur tubuh yang buruk, dehidrasi, dan tingginya asupan kopi (Kandil et al., 2014).

Dari beberapa faktor risiko yang telah diuraikan dari beberapa penelitian di atas, ternyata pemicu timbulnya nyeri kepala salah satunya faktor stres (baik secara mental maupun fisik). Hal ini selaras dengan salah satu penelitian yang sudah dilakukan pada mahasiswa Fakultas 
Kedokteran di Universitas Sam Ratulangi, dalam penelitiannya ini menyebutkan stres dan menstruasi pada wanita menduduki peringkat tertinggi sebagai pencetus terjadinya nyeri kepala primer pada seluruh subyek penelitian yang menderita nyeri kepala (Riyadina, 2014).

\section{METODE}

Metode penelitian yang digunakan dalam penelitian ini adalah metode analitik observasional dengan pendekatan dalam penelitian ini ialah cross sectional. Penelitian ini menggunakan data primer kuesioner sebagai alat ukur. Kuisioner yang digunakan untuk mengukur stres adalah PSS-10, sedangkan untuk mengukur nyeri kepala primer menggunakan Headache Intake Questionnaire, Cleaveland Clinic Canada.

HASIL
Distribusi

frekuensi karakteristik responden mahasiswa program studi kedokteran fakultas kedokteran universitas malahayati tahun 2020 semester 7 berdasarkan jenis kelamin pada penelitian ini didapatkan responden yang berjenis kelamin perempuan yaitu 116 responden (64,4\%). Distribusi responden menurut usia pada tabel 1 didapatkan usia 21 tahun sebanyak 138 responden $(76,7 \%)$. Distribusi responden berdasarkan tingkatan stres dari 180 responden yang mengalami stress ringan sebanyak 2 responden $(1,1 \%)$, yang mengalami stres sedang sebanyak 124 responden (68,9\%), sedangkan stres berat sebanyak 54 responden (30\%). Distribusi responden berdasarkan jenis nyeri kepala primer yang dialami, tipe migraine sebanyak 114 responden $(63,3 \%)$, tipe TTH sebanyak 66 responden $(36,7 \%)$ dan tipe cluster tidak ditemukan pada penelitian ini (0\%).

Tabel 1. Karakteristik Responden

\begin{tabular}{ccc}
\hline Jenis Kelamin & Frekuensi (f) & Persentase (\%) \\
\hline Laki-Laki & 64 & $35,6 \%$ \\
Perempuan & 116 & $64,4 \%$ \\
Total & 180 & $100 \%$ \\
\hline Umur/Usia & Frekuensi (f) & Persentase (\%) \\
\hline 21 & 138 & $76,7 \%$ \\
22 & 42 & $23,3 \%$ \\
Total & 180 & $100 \%$ \\
\hline Tingkat Stres & Frekuensi (f) & Persentase (\%) \\
\hline Stres Ringan & 2 & $1,1 \%$ \\
Stres Sedang & 124 & $68,9 \%$ \\
Stres Berat & 54 & $30 \%$ \\
Total & 180 & $100 \%$ \\
\hline Nyeri Kepala & Frekuensi (f) & Persentase (\%) \\
Primer & & \\
\hline Migrain & 114 & $63,3 \%$ \\
TTH & 66 & $36,7 \%$ \\
Cluster & - & - \\
Total & 180 & $100 \%$ \\
\hline
\end{tabular}


Berdasarkan tabel dibawah ini, tingkat stres berdasarkan jenis kelamin didapatkan perempuan paling banyak mengalami tingkatan stres sedang yakni sebanyak 79 responden $(68,1 \%)$ dan yang paling sedikit mengalami stress ringan yakni sebanyak 2 responden (1,7\%). Begitu juga pada laki-laki paling banyak mengalami tingkatan stress sedang yakni sebanyak 47 responden $(73,4 \%)$ dan pada laki - laki tidak ada yang mengalami stres ringan.

Tabel 2 Tingkat Stres Berdasarkan Jenis kelamin

\begin{tabular}{|c|c|c|c|c|c|c|c|}
\hline \multirow{2}{*}{$\begin{array}{l}\text { Jenis } \\
\text { Kelamin }\end{array}$} & \multicolumn{2}{|c|}{ Stres Ringan } & \multicolumn{2}{|c|}{ Stres Sedang } & \multicolumn{2}{|c|}{ Stres Berat } & Total \\
\hline & $\mathbf{N}$ & $F$ & $\mathbf{N}$ & $\mathbf{F}$ & $\mathbf{N}$ & $F$ & $\mathbf{N}$ \\
\hline $\begin{array}{l}\text { Laki - laki } \\
64 \quad(100 \%)\end{array}$ & 0 & $(0,0 \%)$ & & 47 & $(73,4 \%)$ & 17 & $(26,6 \%)$ \\
\hline $\begin{array}{l}\text { Perempuan } \\
116 \quad(100 \%)\end{array}$ & 2 & $(1,7 \%)$ & & 79 & $(68,1 \%)$ & 35 & $(30,2 \%)$ \\
\hline
\end{tabular}

Berdasarkan tabel 3 jenis nyeri kepala primer berdasarakan Jenis Kelamin dalam penelitian ini nyeri kepala primer yang sering terjadi adalah tipe migrain pada perempuan paling banyak mengalami yakni sebanyak 78 responden $(73,3 \%)$ sedangkan yang paling sedikit terjadi adalah nyeri kepala primer tipe tegang (TTH) pada laki-laki yang mengalami TTH ini sebanyak 28 responden $(39,1 \%)$.

Tabel 3 Jenis Nyeri Kepala Primer Berdasarkan Jenis Kelamin

\begin{tabular}{llcccccc}
\hline Jenis Kelamin & \multicolumn{2}{l}{ Migrain } & $\mathbf{( \% )}$ & TTH & (\%) & \multicolumn{2}{c}{ Total } \\
\cline { 2 - 4 } & $\mathrm{N}$ & $\mathrm{F}$ & $\mathrm{N}$ & $\mathrm{F}$ & $\mathrm{N}$ & $\mathrm{F}$ \\
\hline Laki - laki & 36 & $(60,9 \%)$ & 28 & $(39,1 \%)$ & 64 & $(100 \%)$ \\
Perempuan & 78 & $(73,3 \%)$ & 38 & $(26,7 \%)$ & 116 & $(100 \%)$ \\
\hline
\end{tabular}

Berdasarkan tabel 4 hubungan stres dengan nyeri kepala primer, tingkatan stress yang paling banyak menimbulkan nyeri kepala primer adalah stress sedang dengan nyeri kepala primer tipe migrain yakni sebanyak 97 responden $(85,1 \%)$ sedangkan yang paling sedikit adalah stress ringan dengan nyeri kepala tipe migrain yakni sebanyak 1 responden $(0,9 \%)$.

Tabel 4 Hubungan Stres Dengan Nyeri Kepala Primer

\begin{tabular}{|c|c|c|c|c|c|c|c|c|}
\hline \multirow{3}{*}{$\begin{array}{l}\text { Nyeri } \\
\text { Kepala } \\
\text { Primer }\end{array}$} & \multicolumn{6}{|c|}{ Tingkatan Stres } & \multirow{2}{*}{\multicolumn{2}{|c|}{ Total }} \\
\hline & \multicolumn{2}{|c|}{ Stres Ringan } & \multicolumn{2}{|c|}{ Stres Sedang } & \multicolumn{2}{|c|}{ Stres Berat } & & \\
\hline & $\mathbf{N}$ & $F$ & $N$ & $F$ & $\mathbf{N}$ & $F$ & N & $\mathbf{F}$ \\
\hline $\begin{array}{l}\text { Migrain } \\
(100 \%)\end{array}$ & 1 & $(0,9 \%)$ & 97 & $(85,1 \%)$ & & 16 & $(14 \%)$ & 114 \\
\hline $\begin{array}{l}\text { TTH } \\
(100 \%) \\
\end{array}$ & 1 & $(1,5 \%)$ & 27 & $(41 \%)$ & & 38 & $(57,5 \%)$ & 66 \\
\hline
\end{tabular}




\section{PEMBAHASAN}

Penelitian ini didominasi oleh responden berjenis kelamin perempuan dibandingkan berjenis kelamin laki-laki. Dari penelitian ini didapati bahwa tingkat stres pada responden perempuan lebih tinggi daripada responden laki-laki, yaitu terdiri dari 64 orang $(35,6 \%)$ laki-laki dan 116 orang $(64,4 \%)$ perempuan. Hal ini menunjukkan bahwa tingkat stres dipengaruhi oleh faktor jenis kelamin, dimana perempuan untuk segala hal lebih menggunakan perasaan dibandingkan akal sehingga lebih mudah menjadi stres, sedangkan laki-laki lebih menggunakan akal daripada perasaan sehngga kemungkinan terjadinya stres lebih kecil. Berkaitan dengan tingkat stres pada laki-laki dan perempuan, bahwa perempuan lebih cemas akan ketidakmampuannya dibanding dengan lakilaki, laki-laki lebih aktif, eksploratif, sedangkan perempuan lebih sensitif. Kriteria tingkat stres adalah sama untuk semua jenis kelamin. Akan tetapi, wanita lebih mudah merasakan perasaan bersalah, cemas, peningkatan bahkan penurunan nafsu makan, gangguan tidur, serta gangguan makan. Sesuai dengan American Institute of Stress, bahwa perempuan 2-3 kali lebih rentan terhadap stress dibandingkan lakilaki (American Institute of Stress, 2016).

Responden yang mengalami nyeri kepala primer yaitu migrain sebanyak 114 orang $(63,3 \%)$ dan yang mengalami nyeri kepala tipe tegang (TTH) sebanyak 66 orang $(36,7 \%)$. Ini selaras dengan penelitian yang dilakukan Sjahrir tahun 2004, frekuensi kejadian nyeri kepala primer tipe cluster paling sedikit terjadi disbanding nyeri kepala primer tipe lainnya.
Hasil penelitian ini sesuai dengan penelitian yang pernah dilakukan oleh Gabman dkk (2009), penelitian internasional menemukan prevalensi nyeri kepala primer pada remaja dan dewasa muda akan terus meningkat dalam persentase yang relative tinggi (>50\%). Sjahrir $2004 \mathrm{di}$ medan telah meneliti karakteristik nyeri kepala Migren dan TTH pada 2 SMA di kotamadya Medan di dapatkan hasil pada siswa SMA sebanyak 78\% menderita nyeri kepala primer.

Dari hasil pengolahan data menggunakan IBM SPSS 26.0. Berdasarkan hasil uji statistik chi square dari penelitian ini menunjukkan hasil $p$-value 0,000 (pvalue< 0,05), hasil menunjukkan terdapat hubungan yang bermakna antara tingkat stres dengan nyeri kepala primer pada mahasiswa program studi kedokteran fakultas kedokteran Universitas Malahayati Tahun 2020.

Penelitian dengan hasil serupa juga dilakukan di Semarang, yang menunjukkan adanya hubungan stres kerja dengan kejadian nyeri kepala di antara para pekerja ground handling ( $p$ value $=0,02$ ) (Jatmiputri, 2016). Schramm et al. juga melakukan penelitian tentang hubungan stres dengan nyeri kepala primer dalam suatu studi longitudinal, dan diperoleh hasil bahwa peningkatan frekuensi nyeri kepala primer berhubungan dengan peningkatan intensitas stres (Schramm et al., 2015). Selain itu, penelitian di Yunani menemukan bahwa kejadiankejadian stres merupakan faktor pemicu terbanyak yang menyebabkan kejadian nyeri kepala primer, yaitu sebanyak 83,6\% (Iliopoulos et al., 2015).

Dampak yang disebabkan oleh faktor stres terhadap serangan nyeri kepala dapat terjadi di level perifer 
dan sentral. Pada level perifer, stres dapat mencetuskan inflamasi perivaskular dan ketegangan otot perikranial. Pada level sentral, stres dapat mempengaruhi kontrol neuron supraspinal di nukleus kaudalis trigeminal, menyebabkan peningkatan eksitabilitas di level spinal/trigeminal dan merusak efektivitas sistem antinosiseptif (Nash and Thebarge, 2006).

\section{KESIMPULAN}

Berdasarkan hasil penelitian hubungan stres dengan nyeri kepala primer pada mahasiswa program studi kedokteran fakultas kedokteran Universitas Malahayati Tahun 2020 disimpulkan bahwa :

1. Diketahui prevalensi mahasiswa program studi kedokteran fakultas kedokteran Universitas Malahayati tahun 2020 yang mengalami nyeri kepala primer adalah tipe migrain sebanyak 114 orang $(63,3 \%)$, TTH sebanyak 66 orang $(36,7 \%)$, untuk tipe cluster tidak ditemukan $(0 \%)$.

2. Diketahui prevalensi mahasiswa program studi kedokteran fakultas kedokteran Universitas Malahayati tahun 2020 yang mengalami stres adalah stres sedang yaitu sebanyak 124 orang $(68,9 \%)$, stres ringan sebanyak 2 orang $(1,1 \%)$, dan stress berat sebanyak 54 orang $(30 \%)$.

3. Diketahui karakteristik nyeri kepala primer pada mahasiswa program studi kedokteran fakultas kedokteran Universitas Malahayati berdasarkan jenis kelamin tipe migrain lebih sering terjadi pada perempuan yaitu sebanyak 78 orang $(73,3 \%)$ dan laki laki sebanyak 36 orang $(60,9 \%)$.

4. Diketahui karakteristik tingkatan stres pada mahasiswa program studi kedokteran fakultas kedokteran Universitas Malahayati berdasarkan jenis kelamin tingkatan stres sedang paling sering terjadi pada perempuan sebanyak 79 orang $(68,1 \%)$, dan laki laki sebanyak 47 orang $(73,4 \%)$.

5. Diketahui terdapat hubungan anatara tingkat stres dengan nyeri kepala primer pada mahasiswa program studi kedokteran fakultas kedokteran Universitas Malahayati Tahun 2020 dengan $p=0,000(<0,05)$, nilai $\mathrm{OR} \mathrm{Cl}=3,841$.

\section{DAFTAR PUSTAKA}

American Institute of Stress. (2016) Effect of Stress. USA: American Institute of Stress, Available online at: http://www.stress.org/slide/e ffects-of-stress/; 2016.

Ayzenberg, I., Katsarava, Z., Sborowski, A., Chernysh, M., Osipova, V., Tabeeva, G., \& Steiner, T. J. (2014). Headache-attributed burden and its impact on productivity and quality of life in Russia: Structured healthcare for headache is urgently needed. European Journal of Neurology, 21(5), 758-765. https://doi.org/10.1111/ene. 1 $\underline{2380}$

Iliopoulos, P., Damigos, D., Kerezoudi, E., Limpitaki, G., Xifaras, M., Skiada, D., Tsagkovits, A., \& Skapinakis, P. (2015). Trigger factors in primary headaches subtypes: A cross-sectional study from a tertiary centre in Greece 
Neurology. BMC Research Notes, $\quad 8(1)$, $1-10$. https://doi.org/10.1186/s1310 4-015-1390-7

Kandil, M., Hamed, S. and Fadel, K. (2014). 'Epidemiology of Tension-Type Headache ( TTH ) in Assuit', Journal of Neurology and Neuroscience, vol. 5, no. 1 , pp. 1-16. doi: 10.3823/341.

Nash, J. M., \& Thebarge, R. W. (2006). Understanding psychological stress, its biological processes, and impact on primary headache. Headache, 46(9), 1377-1386. https://doi.org/10.1111/j.152 6-4610.2006.00580.x
Riyadina, W., \& Turana, Y. (2014). Faktor Risiko Dan Komorbiditas Migrain. Buletin Penelitian Sistem Kesehatan, 17(4), 371378. https://media.neliti.com/medi a/publications/20916-ID-riskfactor-and-comorbidity-ofmigraine.pdf

Tepper, S. J. (2013). 3rd Edition, beta version. 1381-1382.

World Health Organization. (2012). Headache Disorder, WHO Media Centre. Available at: http://www. who.int/mediace ntre/factsheets/fs277/en/ (Accessed: 9 June 2017). 